О. С. Гавриш, к.ф.-м.н., доиент,

С. І. Костюк, магістр,

Ю. Ю. Обруч, магістр,

М. О. Багрій, магістр

Черкаський державний технологічний університет

б-р Шевченка, 460, Черкаси, 18006, Україна

\title{
ВІРТУАЛЬНИЙ ІНСТРУМЕНТАРІЙ ДЛЯ ДОСЛІДЖЕННЯ ХВИЛЕВОДУ ПРЯМОКУТНОГО ПЕРЕТИНУ
}

У роботі синтезовано віртуальний стенд у середовищі LabView, який дає можливість провести імітаційне моделювання для визначення параметрів електромагнітної хвилі в прямокутному хвилеводі. Для хвилі заданого типу з довільним сполученням індексів $m$ i n, що поширюється по хвилеводу з заданими геометричними розмірами поперечного перетину, можна визначати критичну довжину хвилі або критичну частоту. Також розроблений віртуальний інструментарій дає змогу досліджувати дисперсію в хвилеводі, оцінювати величину втрат у хвилеводі та коефіиієнт корисної дї̈, визначати окремо для хвиль Е і Н типів характеристичний опір хвилеводу і коефіиієнт відбиття. Отримано аналітичні вирази для розрахунку пробивної потужності хвилеводу при поширенні хвиль Е і Н типів, які також реалізовано у вигляді відповідних віртуальних інструментів. Розроблений віртуальний інструментарій дозволяє організувати дистанційне навчання.

Ключові слова: імітаційне моделювання, прямокутний хвилевід, електромагнітна хвиля, віртуальний стенд, програма LabVIEW.

Вступ. Прямокутний хвилевід є одним із найбільш поширених типів лінії передачі в міліметровому, сантиметровому і в короткохвильовій частині дециметрового діапазону. Він дає можливість передавати досить значні рівні потужності з малим загасанням, $\epsilon$ широкосмуговим і механічно міцним [1-3].

У навчальному процесі для визначення параметрів хвилеводів прямокутного перетину традиційно використовуються фізичні стенди, що складаються 3 генератора хитної частоти типів Я2P-74 ( $\mathrm{f}=0,01-2$ ГГц), Я2P-75 ( $\mathrm{f}=2$ 8,3 ГГц) або Я2P-76 (f = 8,15-18 ГГц), індикатора КСХН і послаблень Я2Р-70, а також комплекту кабелів і направлених розгалужень відповідного діапазону частот. Електричні схеми приладів побудовано з використанням мікропроцесорів, що дає можливість використовувати прилади в складі автоматизованих вимірювальних систем через канал загального користування [4]. Проте за допомогою такого обладнання можна розглядати поширення лише хвилі основного типу $\mathrm{H}_{10} \mathrm{i}$ не вдається врахувати різноманіття вищих типів хвиль Е і Н типів.

Режим роботи лінії передачі характеризується рядом параметрів, які в процесі іiї експлуатації підлягають контролю і підтримуються в певних межах шляхом передбачених

(C) О. С. Гавриш, С. І. Костюк, Ю. Ю. Обруч, М. О. Багрій, 2019 DOI: 10.24025/2306-4412.2.2019.173693 регулювань. Для дослідження хвиль у прямокутному хвилеводі 3 навчальною метою часто цілком достатньо імітаційної комп'ютерної моделі, яка може замінити цілий комплекс коштовної апаратури. Крім того, віртуальні інструменти дають змогу організувати дистанційне навчання, яке було неможливе при використанні традиційної лабораторної бази [5]. Тому створення віртуального стенда в середовищі LabView [5-7] і дослідження за його допомогою параметрів прямокутного хвилеводу $\epsilon$ актуальною задачею.

В роботах $[8,9]$ розглянуто різні варіанти реалізації віртуальної установки в середовищі LabView для дослідження параметрів хвилеводу. В цій роботі пропонується розширити функціональні можливості віртуального стенда, а саме збільшити кількість вимірюваних параметрів за рахунок отримання нових i використання додаткових математичних моделей.

Цілком очевидно, що віртуальний експеримент не може повністю замінити фізичний, але для навчальних цілей він може мати ряд переваг [5, 10]:

- наочна візуалізація результатів експерименту, що сприяє більш повному розумінню досліджуваного фізичного явища; 
- досягається потрібний рівень безпеки при проведенні експерименту, оскільки НВЧ випромінювання $є$ потенційно небезпечним і може потребувати додаткових заходів захисту від нього;

- загальна доступність віртуальних ресурсів при дистанційному навчанні.

Постановка завдання. Метою роботи $\epsilon$ створення віртуального інструментарію в середовищі Labview для дослідження різних типів хвиль у прямокутному хвилеводі на основі використання відомих та отримання нових математичних моделей, для організації дистанційного навчання 3 дисципліни «Технічна електродинаміка».

Припускаємо, що синтезований віртуальний стенд у середовищі LabView дасть можливість за заданими вхідними параметрами розраховувати вихідні для хвиль Е і Н типів 3 довільним сполученням індексів. Як вхідні параметри використовуються такі: «індекс $\mathrm{m} »$, «індекси n», «Ширина хвилеводу а, мм», «Висота хвилеводу b, мм», «Робоча частота, ГГц», «Довжина хвилеводу, см», «Коефіцієнт згасання, дБ/м», «Вхідна потужність, Вт». Розрахунки можуть проводитись для двох типів хвиль: електричних Е і магнітних Н. Вихідними параметрами стенда $є$ : «Критична довжина хвилі, мм», «Критична частота, ГГц», «Довжина хвилі в хвилеводі, мм», «Відносна фазова швидкість», «Втрати в хвилеводі, Дб», «Коефіцієнт корисної дії, \%», «Характеристичний опір, Ом», «Коефіцієнт відбиття», «Вихідна потужність, Вт», «Потужність втрат, Вт».

Вибір математичних моделей $\mathbf{i}$ створення субВІ для обчислення параметрів прямокутного хвилеводу. Для створення віртуального стенда необхідно вибрати математичні моделі, які зв'язують задані вхідні і вихідні параметри. Розглянемо синтез п'яти субВІ (допоміжних віртуальних інструментів), які дадуть змогу обчислювати:

$1)$ критичну довжину хвилі $\left(\lambda_{\text {кр }}\right)_{\mathrm{mn}}$ (або критичну частоту $\left.\left(\mathrm{f}_{\mathrm{кp}}\right)_{\mathrm{mn}}\right)$

$$
\left(\lambda_{\text {кр }}\right)_{\mathrm{mn}}=\frac{2}{\sqrt{\left(\frac{\mathrm{m}}{\mathrm{a}}\right)^{2}+\left(\frac{\mathrm{n}}{\mathrm{b}}\right)^{2}}},
$$

де a , b - лінійні розміри хвилеводу;

m, n - кількість стоячих напівхвиль, що укладаються уздовж координат $\mathrm{x}$ та $\mathrm{y}$ відповідно;

(C) О. С. Гавриш, С. І. Костюк, Ю. Ю. Обруч, М. О. Багрій, 2019 DOI: 10.24025/2306-4412.2.2019.173693
2) відносну фазову швидкість $V_{\phi} / \mathrm{C}$ i довжину хвилі у хвилеводі $\lambda_{\text {хв }}$ :

$$
\frac{\mathrm{V}_{\phi}}{\mathrm{C}}=\frac{1}{\sqrt{\varepsilon \mu-\lambda^{2} / \lambda_{\mathrm{\kappa p}}^{2}}},
$$

де C - швидкість світла у вакуумі; $\varepsilon, \mu$ - діелектрична і магнітна проникності середовища,

$$
\lambda_{\text {хв }}=\frac{V_{\phi}}{f}=\frac{\lambda}{\sqrt{\varepsilon \mu-\left(\lambda / \lambda_{\text {кр }}\right)^{2}}} ;
$$

3) втрати в лінії передач L, вихідну потужність $\mathrm{P}_{\text {вих }}$, потужність втрат $\mathrm{P}_{\text {втрат }}$ і коефіцієнт корисної дії $\eta$ :

$$
\mathrm{L}=10 \lg \frac{\mathrm{P}_{\text {вх }}}{\mathrm{P}_{\text {вих }}} \cong 8,68 \alpha \mathrm{l},
$$

де $\alpha$ - стала згасання; 1 - довжина лінії передач,

$$
\begin{gathered}
\mathrm{P}_{\text {вих }}=\mathrm{P}_{\text {вх }} \mathrm{e}^{-2 \alpha \mathrm{l}}, \\
\mathrm{P}_{\text {втрат }}=\mathrm{P}_{\text {вх }}-\mathrm{P}_{\text {вих }}, \\
\eta=\frac{\mathrm{P}_{\text {вих }}}{\mathrm{P}_{\text {вх }}} ;
\end{gathered}
$$

4) хвильовий опір хвилеводу $Z_{c}$ i коефіцієнт відбиття при відкритому кінці хвилеводу $\dot{\Gamma}$ :

$$
\begin{gathered}
\mathrm{Z}_{\mathrm{cE}}=\mathrm{Z}_{0} \sqrt{1-\left(\lambda / \lambda_{\text {кр }}\right)^{2}}, \\
\mathrm{Z}_{\mathrm{cH}}=\frac{\mathrm{Z}_{0}}{\sqrt{1-\left(\lambda / \lambda_{\text {кр }}\right)^{2}}},
\end{gathered}
$$

де $\mathrm{Z}_{0}=377$ Ом - характеристичний опір вакууму.

У загальному випадку коефіцієнт відбиття може бути виражений через характеристичний опір розглянутої лінії $Z_{c}$ й опір навантаження $Z_{\text {н }}$ :

$$
|\dot{\Gamma}|=\left|\frac{Z_{\mathrm{H}}-Z_{\mathrm{c}}}{Z_{\mathrm{H}}+\mathrm{Z}_{\mathrm{c}}}\right| ;
$$

5) пробивну потужність хвилеводу $\mathrm{P}_{\text {проб }}$

$$
\mathrm{P}=\frac{1}{2} \int_{0}^{\mathrm{a}} \int_{0}^{\mathrm{b}}\left(\dot{\mathrm{E}}_{\mathrm{x}} \dot{\mathrm{H}}_{\mathrm{y}}^{*}-\dot{\mathrm{E}}_{\mathrm{y}} \dot{\mathrm{H}}_{\mathrm{x}}^{*}\right) \mathrm{dxdy}
$$

У рівнянні (11) використовуються вирази складових полів біжучої хвилі типу $\mathrm{E}_{\mathrm{mn}}$, $\mathrm{H}_{\mathrm{mn}}[1-3]$. 
Можна показати, що після громіздких розрахунків рівняння для визначення пробивної потужності при хвилі типу $\mathrm{E}_{\mathrm{mn}}$ набуває вигляду

$$
\begin{array}{r}
\left(\mathrm{P}_{\text {проб } 1}\right)_{\mathrm{E}_{\mathrm{mn}}}=\frac{\mathrm{E}_{\text {проб }}^{2} \mathrm{~V}_{\phi} \varepsilon \varepsilon_{0} \mathrm{a}^{2}}{8 \mathrm{~m}^{2}}\left(\frac{\mathrm{b}}{\mathrm{a}} \mathrm{m}^{2}+\frac{\mathrm{a}}{\mathrm{b}} \mathrm{n}^{2}\right), \\
\left(\mathrm{P}_{\text {проб } 2}\right)_{\mathrm{E}_{\mathrm{mn}}}=\frac{\mathrm{E}_{\text {проб }}^{2} \mathrm{~V}_{\phi} \varepsilon \varepsilon_{0} \mathrm{~b}^{2}}{8 \mathrm{n}^{2}}\left(\frac{\mathrm{b}}{\mathrm{a}} \mathrm{m}^{2}+\frac{\mathrm{a}}{\mathrm{b}} \mathrm{n}^{2}\right) .
\end{array}
$$

Експериментально встановлено, що при нормальному атмосферному тиску для сухого повітря пробивна напруженість електричного поля $\mathrm{E}_{\text {проб }}$ в діапазоні сантиметрових хвиль має порядок 30 кВ/см [1-3].

При різних значеннях геометричних розмірів хвилеводу $\mathrm{a} \times \mathrm{b}$ i сполученнях індексів $\mathrm{m}, \mathrm{n}$ можливі різні співвідношення між потужностями, що описуються виразом (12). 3 двох отриманих значень потрібно обирати менше, оскільки воно вказує на величину потужності, при якій вже може настати електричний пробій по відповідній стінці хвилеводу.

Аналогічно до виразу (12) було отримано розрахункове рівняння для визначення пробивної потужності при поширенні хвилі типу $\mathrm{H}_{\mathrm{mn}}$

$$
\begin{array}{r}
\left(\mathrm{P}_{\text {проб1 } 1}\right)_{\mathrm{H}_{\mathrm{mn}}}=\frac{\mathrm{E}_{\text {проб }}^{2} \mathrm{~b}^{2}}{8 \mathrm{n}^{2} \mathrm{~V}_{\phi} \mu \mu_{0}}\left(\frac{\mathrm{a}}{\mathrm{b}} \mathrm{n}^{2}+\frac{\mathrm{b}}{\mathrm{a}} \mathrm{m}^{2}\right), \\
\left(\mathrm{P}_{\text {проб } 2}\right)_{\mathrm{H}_{\mathrm{mn}}}=\frac{\mathrm{E}_{\text {проб }}^{2} \mathrm{a}^{2}}{8 \mathrm{~m}^{2} \mathrm{~V}_{\phi} \mu \mu_{0}}\left(\frac{\mathrm{a}}{\mathrm{b}} \mathrm{n}^{2}+\frac{\mathrm{b}}{\mathrm{a}} \mathrm{m}^{2}\right) .
\end{array}
$$

Як $\mathrm{i}$ для хвилі $\mathrm{E}_{\mathrm{mn}}$, при різних значеннях геометричних розмірів хвилеводу $\mathrm{a} \times \mathrm{b}$ i різних сполученнях індексів $\mathrm{m}, \mathrm{n}$ можливі різні співвідношення між потужностями, що описуються виразом (13).

У випадку, якщо один із індексів у позначенні типу хвилі нульовий, то величина пробивної потужності має один варіант розрахунку. Якщо обидва індекси відмінні від нуля, то 3 двох отриманих значень потрібно обирати те, яке менше.

Для структуризації програми підготуємо ряд допоміжних віртуальних інструментів, використовуючи вирази (1)-(13). Приклад реалізації субВІ «Критична довжина хвиля» 3 використанням формульного вузла зображено на рисунку 1. Іконки субВI та назви їх входів та виходів наведено в таблиці 1.

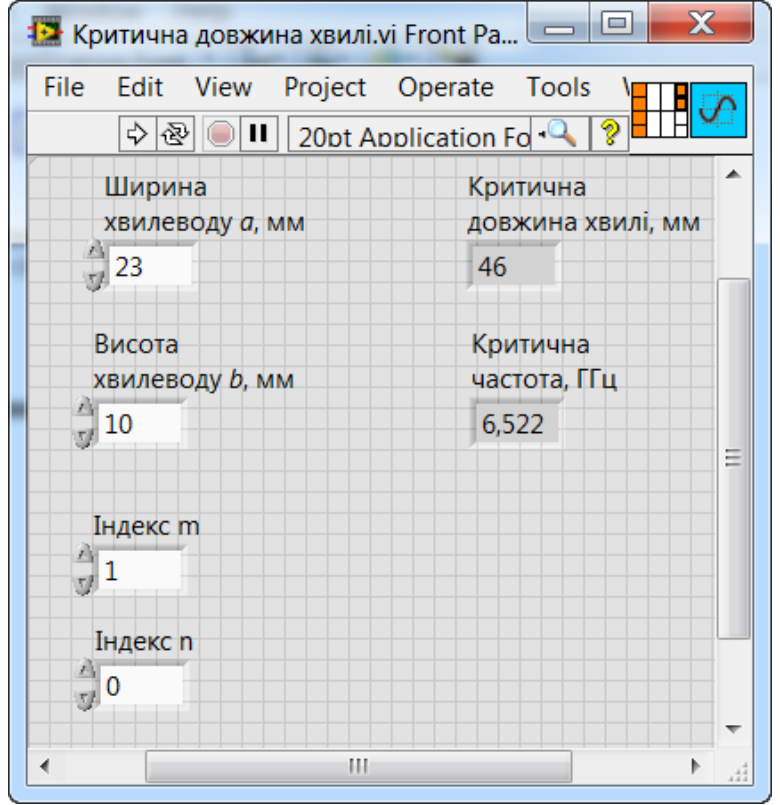

a)

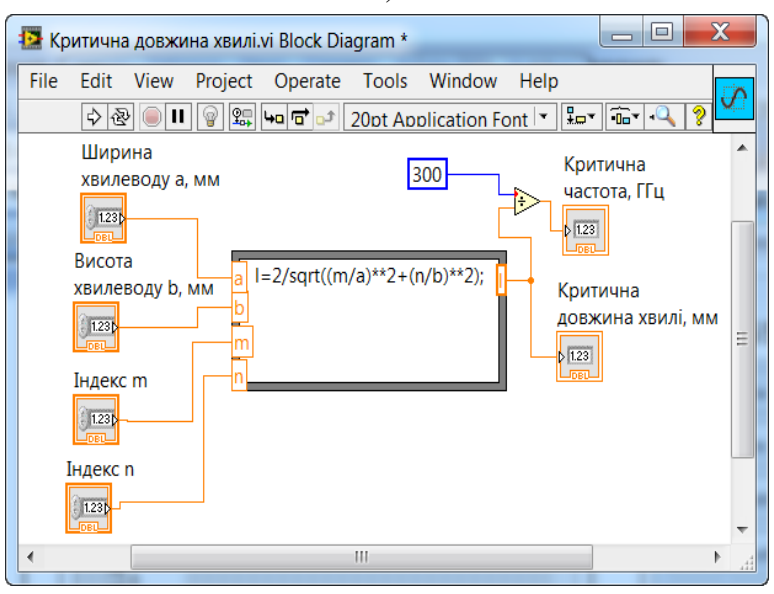

б)

Рисунок 1 - Лицьова панель (а) і блок-схема (б) субВI «Критична довжина хвилі»

\section{Таблиця 1 - Допоміжні прилади (субВI)}

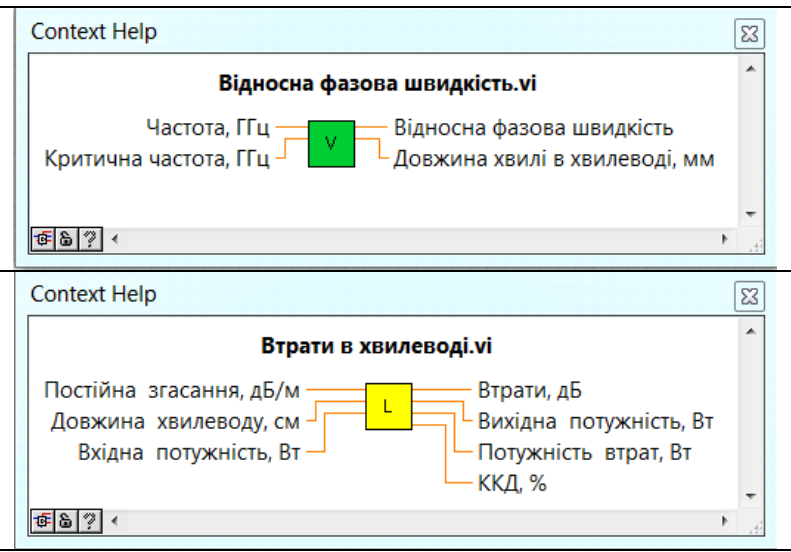




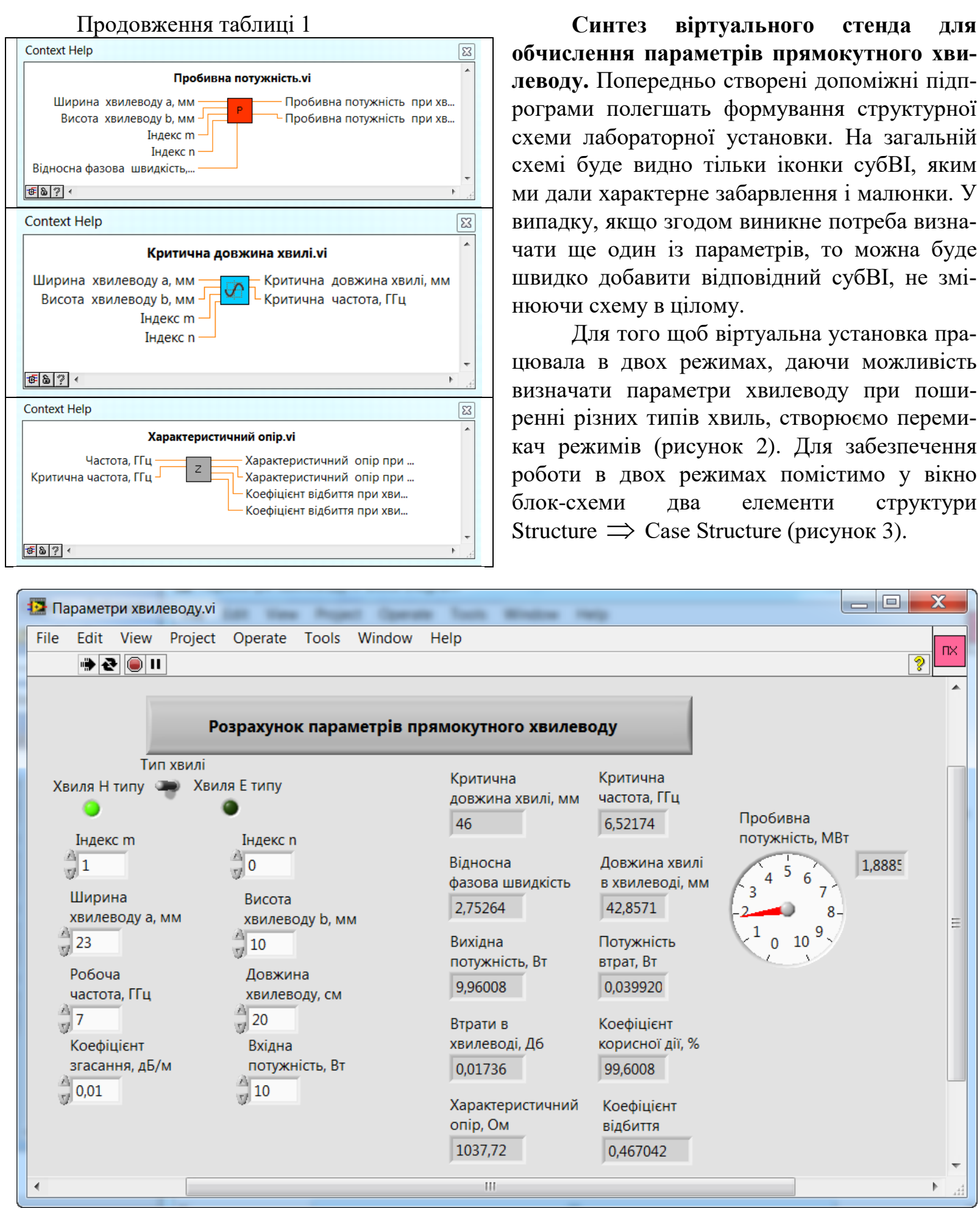

Рисунок 2 - Лицьова панель ВI «Параметри прямокутного хвилеводу»

При поширенні хвиль Е і Н типів частина вихідних параметрів буде однаковою, а три параметри (характеристичний опір, коефіцієнт відбиття і пробивна потужність) можуть відрізнятися.

Яка 3 двох сторінок кожної структури виконуватиметься, залежить від положення (c) О. С. Гавриш, С. І. Костюк, Ю. Ю. Обруч, М. О. Багрій, 2019 DOI: 10.24025/2306-4412.2.2019.173693 перемикача режимів «Тип хвилі». Для цього термінал перемикача підключаємо до терміналу вибору на лівій стороні рамки кожної структури. До терміналу перемикача підключаємо світлодіод «Хвиля Е типу» і через оператор логічного заперечення Not світлодіод «Хвиля Н типу». При перемиканні світитиметься діод 
відповідного режиму і виконуватиметься програма $з$ відповідної сторінки структури Case.

При значенні «True» на терміналі вибору виконується розрахунок параметрів хвилеводу при поширенні хвилі Е типу. При значенні «False» на терміналі вибору виконується розрахунок параметрів хвилеводу при поширенні хвилі Н типу. Вікно з відповідними структурами Case зображено на рисунку 3.

Розглянемо роботу структури Case при визначенні пробивної потужності. Для визначення величини пробивної потужності при різних типах хвилі було синтезовано субВI «Пробивна потужність». 3 палітри Functions вибираємо Select a VI. 3 вікна, що відкрилося, поміщаємо у вікно структури Case структурної схеми створений субВI. При значенні «True» на терміналі вибору вихідним пара- метром буде лише «Пробивна потужність при хвилях Е», а інший сигнал «Пробивна потужність при хвилях Н» не задіюється. Проте при значенні «False» на термінал вибору подається другий параметр, а перший не використовується.

Аналогічно працюватиме структура Case при визначенні характеристичного опору і коефіцієнта відбиття. Відмінність полягає в тому, що робота в структурі Case здійснюється 3 субВI «Характеристичний опір».

Для визначення решти параметрів хвилеводу скористаємося субВI, описаними в таблиці 1. 3 палітри Functions вибираємо Select a VI i розміщуємо субВI між регуляторами й індикаторами. Термінали регуляторів, субВІ та індикаторів сполучаємо відповідно до схеми (рисунок 3).

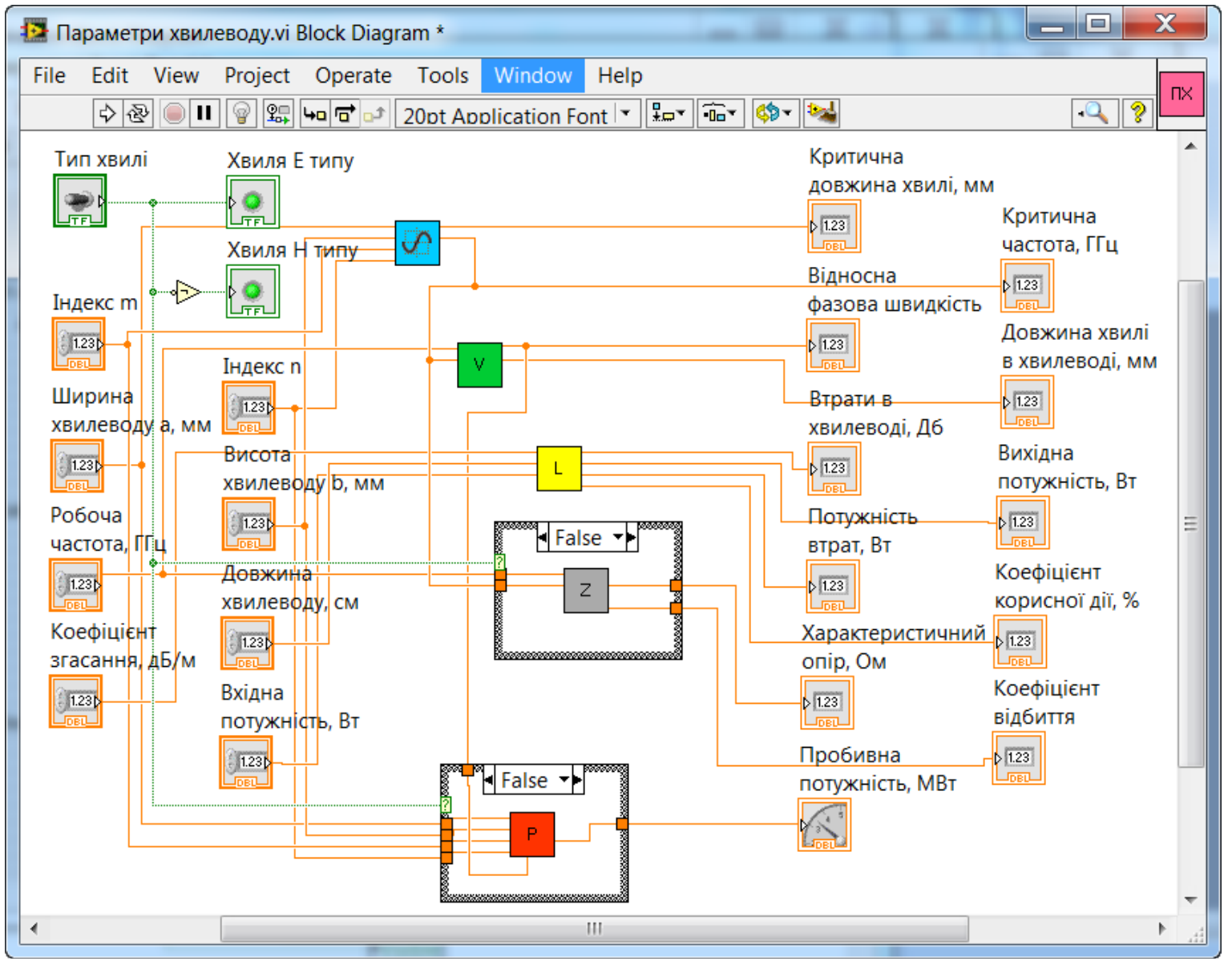

Рисунок 3 - Блок-схема ВI «Параметри хвилеводу» при поширенні хвилі Н типу

Висновки. Синтезований віртуальний стенд $є$ зручним інструментальним засобом для дослідження параметрів і характеристик прямокутного хвилеводу і при використанні його в навчальному процесі сприятиме покращенню розуміння фізичних процесів, що (C) О. С. Гавриш, С. І. Костюк, Ю. Ю. Обруч, М. О. Багрій, 2019 DOI: 10.24025/2306-4412.2.2019.173693 відбуваються при поширенні хвиль Е і Н типів у хвилеводі. Цією програмою дуже зручно виконувати розрахунки для конкретних задач, а саме для розрахунку параметрів хвилеводу для різних типів хвиль. Крім того, $\epsilon$ ще одна суттєва перевага - невеликі матері- 
альні та часові затрати при роботі з програмою. Запропоновані математичні моделі для розрахунку пробивної потужності дають можливість здійснити оптимальний вибір типу хвилі за зазначеним критерієм. Використання сучасних технологій віртуальних приладів надає переваги представленій розробці при організації дистанційного навчання.

\section{Список літератури}

[1] А. С. Андрущак, 3. Ю. Готра, та О. С. Кушнір, Прикладна електродинаміка інформаційних систем: навч. посіб. Львів: Вид-во Львів. політехніки, 2012.

[2] О. С. Гавриш, Методичні вказівки до виконання курсової роботи з дисиипліни «Електродинаміка та розповсюдження радіохвиль» для студентів спеціальноcmi 6.050901 «Радіотехніка». Черкаси: ЧДТУ, 2015.

[3] Ю. В. Пименов, В. И. Вольман, и А. Д. Муравцов, Техническая электродинамика. Москва: Радио и связь, 2000.

[4] О. С. Гавриш, та В. В. Коваль, Методичні вказівки до виконання лабораторних робіт із дисципліни «Пристрої мікрохвильового та оптичного діапазонів» для студентів спечіальності «Радіотехніка» освітньо-кваліфікаційних рівнів "спеціаліст» та «магістр» усіх форм навчання. Черкаси: ЧДТУ, 2015.

[5] Ю. К. Евдокимов, В. Р. Линдваль, и Г. И. Щербаков, LabVIEW для радиоинженера: от виртуальной модели до реального прибора. Практическое руководство для работь в программной cpeде LabVIEW. Москва: ДМК Пресс, 2007.

[6] А. Я. Суранов, LabVIEW 8.20: справочник по функциям. Москва: ДМК Пресс, 2007.

[7] Ю. К. Евдокимов, В. Р. Линдваль, и Г. И. Щербаков, LabVIEW в нaучных ucследованиях. Москва: ДМК Пресс, 2012.

[8] В. Р. Линдваль, Методические указания $\kappa$ выполнению лабораторной работы № ВИ-107 «Параметры волн в прямоугольном металлическом волноводе». Казань: КГТУ, 2006.

[9] Т. С. Василюк, Ю. И. Гришалевич, и А. Б. Прошин, "Компьютерная лабораторная работа «Исследование диспер- сионных явлений, возникающих при передаче сигналов по прямоугольному волноводу»", Т-СОММ - Телекоммуникациии и транспорт, № 11, с. 62-65, 2013.

[10] О. С. Гавриш, та П. В. Лифар, "Віртуальний лабораторний стенд для дослідження генератора на магнетроні", Bicник Черкаського державного технологічного університету, № 2, с. 127-129, 2011 (Технічні науки).

\section{References}

[1] A. S. Andrushchak, Z. Yu. Gotra, and O. S. Kuchnir, Applied electrodynamics of information systems. Lviv: Vyd-vo Lviv. politehnily, 2012 [in Ukrainian].

[2] O. S. Havrysh, Methodical instructions for the implementation of course work on the discipline "Electrodynamics and radio waves propagation" for students of the specialty 6.050901 "Radio engineering". Cherkasy: ChDTU, 2015 [in Ukrainian].

[3] Yu. V. Pimenov, V. I. Volman, and A. D. Muravtsov, Technical electrodynamics. Moscow: Radio i svyaz, 2000 [in Russian].

[4] O. S. Havrysh, and V. V. Koval, Methodical instructions for the implementation of laboratory works on the discipline "Microwave and optical bands" for students specializing in "Radio Engineering" of the educational qualification levels "specialist" and "master" of all forms of training. Cherkasy: ChDTU, 2015 [in Ukrainian].

[5] Yu. K. Evdokimov, V. R. Lindval, and G. I. Shcherbakov, LabVIEW for radio injector: from virtual model to real device. Practical guide for LabVIEW software. Moscow: DMK Press, 2007 [in Russian].

[6] A. Ya. Suranov, LabVIEW 8.20: functional reference. Moscow: DMK Press, 2007 [in Russian].

[7] Yu. K. Evdokimov, V. R. Lindval, and G. I. Shcherbakov, LabVIEW in research. Moscow: DMK Press, 2012 [in Russian].

[8] V. R. Lindval, Methodical instructions for laboratory work no. VI-107 "Parameters of waves in a rectangular metal waveguide". Kazan: KGTU, 2006 [in Russian].

[9] T. S. Vasilyuk, Yu. I. Grishalevich, and A. B. Proshin, "Computer laboratory work "Investigation of dispersion phenomena 
that occur when transmitting signals through a rectangular waveguide", $T$ COMM - Telecommunications and Transport, no. 11, pp. 62-65, 2013 [in Russian].
[10] O. S. Havrysh, and P. V. Lifar, "Virtual laboratory bench for the study of a generator on a magnetron", Visnyk Cherkaskogo derzhavnogo tehnologichnogo universytetu, no. 2, pp. 127-129, 2011 [in Ukrainian].

O. S. Havrysh, Ph. D., associate professor,

S. I. Kostiuk, master,

Yu. Yu. Obruch, master,

M. O. Bagrii, master

Cherkasy State Technological University

Shevchenko blvd, 460, Cherkasy, 18006, Ukraine

\section{VIRTUAL TOOLS FOR RESEARCH OF RECTANGULAR WAVEGUIDE}

The rectangular waveguide is the most common type of transmission line in millimeter, centimeter, and short-wave part of decimeter range. It allows to transmit quite significant levels of power with a small attenuation, is broadband and mechanically strong.

The mode of operation of the transmission line is characterized by a number of parameters, which during its operation are subject to control and are maintained within certain limits by the prescribed adjustments. In order to study waves in a rectangular waveguide for educational purposes, it is often enough to simulate a computer model that can replace a complex of valuable equipment.

In this work, a virtual table in a LabView environment, which allows to carry out simulation in order to determine electromagnetic wave parameters in a rectangular waveguide, is synthesized. For a wave of a given type with arbitrary coupling of $m$ and $n$ indices propagating over a waveguide with given geometric dimensions of the cross section, it is possible to determine critical wavelength or critical frequency. Also, the developed virtual toolkit allows to investigate the dispersion in the waveguide, to estimate the value of losses in the waveguide and the efficiency, to determine, separately for the waves of $E$ and $H$ types, characteristic resistance of the waveguide and reflection coefficient. Analytical expressions are obtained to calculate the breakdown power of a waveguide in the propagation of waves of $E$ and $H$ types, which are also implemented as appropriate virtual instruments. The developed virtual toolkit allows to organize distance learning.

The synthesized virtual table is a convenient tool for studying the parameters and characteristics of a rectangular waveguide, and when used in the learning process, it will contribute to improving the understanding of the physical processes occurring in the propagation of wavelengths of $E$ and $H$ types in the waveguide.

Keywords: simulation modeling, rectangular waveguide, electromagnetic wave, virtual table, LabVIEW program.

Стаття надійшла 17.07.2019

Прийнято 06.08.2019 